\title{
Autologous Transplant in Lymphoma: Experience in a Limited Resource Mexican Reference Center
}

Espinosa-Bautista Karla A, Armengol-Alonso Alejandra, Castro-Sánchez Andrea, Pérez-Álvarez Sandra I and León Eucario*

National Cancer Institute in México, Av. San Fernando 22 Tlalpan Sección XVI Ciudad de México, C.P 14080, Mexico

*Corresponding author: León-Rodríguez Eucario, National Cancer Institute in México, INNSZ: Av Vasco De Quiroga \# 15, Tlalpan, Belisario Domínguez Section XVI, 14080 Mexico City, DF, Mexico, Tel: 555487 0900; E-mail: eucarios@hotmail.com

Received date: Jan 30, 2015, Accepted date: Apr 01, 2015, Publication date: Apr 04, 2015

Copyright: (C) 2015 Karla AEB, et al. This is an open-access article distributed under the terms of the Creative Commons Attribution License, which permits unrestricted use, distribution, and reproduction in any medium, provided the original author and source are credited.

\begin{abstract}
Lymphomas are a heterogeneous group of lymphoproliferative disorder. Treatment of these patients includes chemotherapy and bone marrow transplantation depending on the disease's sub-type and clinical stage. Autologous bone marrow transplantation has been performed in México at the Instituto Nacional de Ciencias Médicas y Nutrición Salvador Zubirán in Non Hodgkin Lymphomas (NHL) and Hodgkin Lymphomas $(\mathrm{HL})$ patients with a poor prognosis during the past 11 years, with a modified BEAM conditioning regimen. The estimated 5-year survival was $65 \%(91 \%$ in $\mathrm{HL}$ and $78 \%$ in $\mathrm{NHL})$ and disease-free survival $51 \%$, values similar to other published series. T-cell lymphomas were analyzed separately, yielding a DFS and OS of $73 \%$ and $73 \%$, respectively. These results are higher to that reported by other groups. In summary, patients with high risk lymphoma can be salvaged with HSCT with a modified conditioning regimen that allows minimize cost and time in developing countries.
\end{abstract}

Keywords: Lymphoma; Autologous transplant; T-Cell Lymphoma; Latinamerica

\section{Introduction}

Lymphomas are a heterogeneous group of lymphoproliferative disorders of B, T or NK lymphocyte origin. Non-Hodgkin's lymphomas (NHL) account for $4 \%$ of all malignancies, with 69,740 cases reported in 2013 in the USA. Hodgkin's lymphoma (HL) has a lower incidence, with 9290 cases reported in the same time period [1]. Mexico does not have records on lymphoma incidence rates but in the last Histopathological Registry of Malignant Neoplasms (HRMN) obtained in 2006, 5864 NHL and 1202 HL cases were reported. Follicular NHL was the most common sub-type (37\%) [2].

Treatment of lymphoma patients depends on the disease's sub-type and clinical stage. A chemotherapy regimen including Cyclophosphamide, Doxorubicin, Vincristine, Prednisone and Rituximab (R-CHOP) is considered the standard first-line therapy of Diffuse Large B-Cell (DLBC) NHL. In spite of this treatment, up to 30 to $40 \%$ of all high-grade lymphomas will not respond to first-line therapy or will recur within the following two years [3]. Patients that respond to a second line chemotherapy, are candidates to consolidation with high-dose chemotherapy followed by Autologous Hematopoietic Stem Cell Transplant (HDC-AHSCT).

Up to $90 \%$ of patients with early stage HL (I and IIa) respond to systemic chemotherapy ABVD (Adriamycin, Bleomycin, Vinblastine and Dacarbazine), COPP (Cyclophosphamide, Oncovin, Procarbazine, Prednisone) /ABVD and BEACOPP (Bleomycin, Etoposide, Adriamycin, Cyclophosphamide, Oncovin, Procarbazine, Prednisone) and/or radiotherapy (RT) [4]. However, in advanced stages (bulky disease $>10 \mathrm{~cm}$, presence of symptoms or clinical stage III/IV), $10 \%$ of patients will not respond to treatment and 20 to $30 \%$ of responders will relapse [4,5]. Treatment with HDC-AHSCT is the regimen of choice in these patients. Two randomized phase III trials showed major freedom from treatment failure (FFTF) in these patients when comparing HDC- AHSCT versus standard dose chemotherapy (CT) [6,7].

AHSCT has been performed at the Instituto Nacional de Ciencias Médicas y Nutrición Salvador Zubirán in NHL patients with a poor prognosis during their first complete remission (CR), in patients with chemosensitive disease during the first and second relapse and in patients with refractory HL in their second CR or with relapsing chemosensitive disease. This report presents the Institute's experience over the past 11 years.

\section{Material and Methods}

\section{Patients}

We conducted a retrospective analysis of patients with the diagnosis of T-cell NHL (anaplastic T-cell NHL, cytotoxic T-cell NHL, centrofacial T-cell NHL, angioimmunoblastic T-cell NHL, NOS T-cell NHL) and mantle cell lymphoma in first complete remission and diffuse large B cell NHL in chemosensitive relapse as well as HL patients (nodular sclerosis, mixed cellularity, lymphocyte depleted and non-specified disease) in chemosensitive relapse; all underwent autologous transplant at the Instituto Nacional de Ciencias Médicas y Nutrición Salvador Zubirán between January 1990 and December 2012. All patients had previously signed a consent form approved by the Institute's Ethics Committee.

\section{Collection}

Granulocyte colony-stimulating factor (G-CSF) was administered to all patients, $10 \mathrm{mcg} / \mathrm{kg} /$ day for five to six days and cell collection was conducted on an ambulatory basis on days four, five and six if necessary, in order to obtain over $2 \times 10^{6} / \mathrm{kg} / \mathrm{CD} 34^{+}$cells by apheresis. The apheresis harvest was refrigerated until infusion (no more than 5 
Citation: Karla AEB, Alejandra AA, Andrea CS, Sandra IPA, Eucario L (2015) Autologous Transplant in Lymphoma: Experience in a Limited

Page 2 of 6

days). We avoid using cryopreservation of blood products in order to reduce costs.

For the three patients that received tandem transplant, the apheresis for the second transplant was stored in $\mathrm{ACD}-\mathrm{A}$ at $-180^{\circ} \mathrm{C}$, in $60 \mathrm{ml}$ bags.

\section{Conditioning regimen}

Patients were conditioned with high-dose BEAM chemotherapy (Carmustine BCNU IV, $300 \mathrm{mg} / \mathrm{m}^{2}$ infused over 3 hours on day- 3 , Cytosine Arabinoside IV, $1000 \mathrm{mg} / \mathrm{m}^{2}$ in two doses on day-2, Etoposide IV, $800 \mathrm{mg} / \mathrm{m}^{2}$ in three doses on days -3 and -2 and Melphalan PO, $140 \mathrm{mg} / \mathrm{m}^{2}$ on day-1). Prophylactic Ciprofloxacin (250 $\mathrm{mg}$ bid), Fluconazole (100 mg bid) and Acyclovir (250 mg IV q 8h) were administered to all patients until the granulocyte count was above 500 total neutrophiles. The bone marrow infusion was conducted on day 0 . All transplants were performed in positive pressure rooms with no associated isolation measures.

\section{Transfusion policies}

Packed red cell (PRC) units were transfused if anemia symptoms were present (tachycardia, hypotension, dyspnea) or the patient's hemoglobin value was below $8 \mathrm{mg} / \mathrm{dL}$. Platelets were also administered if the total platelet count was below $20 \times 10^{9} / \mathrm{L}$ or if it was $30 \times 10^{9} / \mathrm{L}$ and the patient developed bleeding or fever.

\section{Response and toxicity criteria}

Patient response before and after transplant was evaluated by computed axial tomography (CAT) and/or PET-CT in accordance with Cheson's criteria [8] in NHL cases and Deauville's PET criteria [9] in HL.

Toxicity after transplantation was determined following the Common Toxicity Criteria for Adverse Events version 4.0 (CTCAE) [10].

\section{Statistical Analysis}

Continuous variables were expressed as central tendency measures, and dichotomous variables as frequencies and percentages. Analyses of RFS and OS estimates were obtained by Kaplan- Meier's method and contrast between survival curves of each group was determined by log rank test. A two-sided $\mathrm{p}$ value $<0.05$ was considered statistically significant. All analyses were performed with SPSS software (v. 21).

\section{Results}

Thirty nine (39) lymphoma patients were transplanted (Table 1): 24 had NHL and 15 had HL. The patients' age ranged between 7 and 64 years at diagnosis (median: 31 years); 17 were female (44.4\%) and 22 were male $(55.6 \%)$. Patients with NHL were treated with first-line CT consisting of CHOP without Rituximab because of economic limitations. First-line treatment for HL patients was ABVD. Rescue chemotherapy regimens included ICE (Ifosfamide, Carboplatin, Etoposide), ESHAP (Etoposide, Cytarabine, Methylprednisolone, Cisplatin) or DHAP (Dexamethasone, Cytarabine, Cisplatin) in both types of lymphoma.

\begin{tabular}{|c|c|c|}
\hline Gender & No. & $\%$ \\
\hline Female & 17 & 44.4 \\
\hline Male & 22 & 55.6 \\
\hline Age & $31(7-64)$ & \\
\hline Age at transplantation Lymphoms & $34(18-65)$ & \\
\hline \multicolumn{3}{|l|}{ Non Hodgkin Lymphoma } \\
\hline Anaplastic $T$ cell & 5 & 12.8 \\
\hline Cytotoxic T cell & 5 & 12.8 \\
\hline Mantle cell & 4 & 10.3 \\
\hline DLBC & 3 & 7.7 \\
\hline Centrofacial $\mathrm{T}$ cell & 3 & 7.7 \\
\hline Angioimmunoblastic $T$ & 3 & 7.7 \\
\hline NOS T cell & 1 & 2.6 \\
\hline \multicolumn{3}{|l|}{ Hodgkin Lymphoma } \\
\hline Nodular Sclerosis & 6 & 15.4 \\
\hline Mixed Cellularity & 6 & 15.4 \\
\hline Lymphocyte depleted & 1 & 2.6 \\
\hline
\end{tabular}


Citation: Karla AEB, Alejandra AA, Andrea CS, Sandra IPA, Eucario L (2015) Autologous Transplant in Lymphoma: Experience in a Limited Resource Mexican Reference Center . J Blood Disorders Transf 6: 266. doi:10.4172/2155-9864.1000266

Page 3 of 6

\begin{tabular}{|c|c|c|}
\hline NOS LH & 2 & 5.1 \\
\hline \multicolumn{3}{|c|}{ Stage at Transplantation } \\
\hline $1 \mathrm{CR}$ & 10 & 25.6 \\
\hline $2 \mathrm{CR}$ & 15 & 38.4 \\
\hline $3 \mathrm{CR}$ & 2 & 5.2 \\
\hline Relapse & 4 & 10.2 \\
\hline $1 \mathrm{PR}$ & 2 & 5.1 \\
\hline $2 \mathrm{PR}$ & 5 & 12.8 \\
\hline $3 \mathrm{PR}$ & 1 & 2.7 \\
\hline Neutrophil graft & $11(9-22)$ & \\
\hline Platelet graft & $10(0-29)$ & \\
\hline
\end{tabular}

Table 1: Characteristics of 39 adults with Lymphoma.

The age of patients at AHSCT ranged between 18 and 65 years, with a median of 34 years: 10 patients $(25.6 \%)$ were in complete remission (CR), 15 were in second CR (38.4\%), 2 were in third CR (5.2\%), 4 had relapsed (10.2\%), 2 were in first partial remission (PR) (5.1\%), 5 were in second PR (12.8\%) and 1 was in third PR (2.7\%).

\section{Graft}

The source of hematopoietic progenitor cells was peripheral blood $(\mathrm{PB})$ in 35 patients $(89.7 \%)$, not primed bone marrow (BM) in 3 (7.6\%) and $\mathrm{BM}+\mathrm{PB}$ in 1 (2.5\%). The median number of infused CD34+ cells was $3.80 \times 10^{6} / \mathrm{kg}$ (range: $0.99 \times 10^{6} / \mathrm{kg}$ to $8.5 \times 10^{6} / \mathrm{kg}$ ). Neutrophil and platelet grafting was achieved in $100 \%$ of the patients within a median of 11 days for neutrophils ( $\min 9, \max 22$ days) and 10 days for platelets ( $\min 0, \max 29$ days). The median duration of hospitalization was 20 days, ranging between 15 and 39 days. The median number of transfused PRC units was 1, ranging between 0 and 9. The median number of transfused platelet units was 2 (range $0-12$ ).

\section{Toxicity}

Grade III-IV non-hematological toxicity developed in 2 patients (5.1\%). One patient developed hepatotoxicity and another, gastrointestinal toxic manifestations. Both patients recovered with antibiotic and symptomatic treatment. Twenty-one (21)(53.8\%) patients developed infectious processes: 10(25.6\%) had fever with unidentified infection foci, $4(10.3 \%)$ had urinary tract infections, $25.1 \%)$ developed pneumonia, 2(5.5\%) had catheter-related infections, 2(5.5\%) had infectious gastroenteritis and one (2.6\%) had soft tissue infection.

\section{Tandem transplant}

Three patients with HL that at AHSCT had high risk characteristics (bulky disease $>10 \mathrm{~cm}$, B symptoms or stage III/IV) underwent tandem transplants. After the first transplant, all three had PETdocumented partial responses. After leukocyte and platelet recoveries, a second transplant was performed within the following 3 months and after the same conditioning regimen. They developed non- hematological grade I-II toxicity. After a median follow-up of 28 months, all three patients are alive and in complete remission.

\section{Mortality, overall survival and disease-free survival}

Transplant-related mortality by days 30 and 100 was $2.5 \%$ (one patient) due to pneumonia and secondary sepsis with no isolation of the causative microorganism. During follow-up, 14 patients relapsed or their disease progressed. Relapse developed after a median of 13 months (range: 1 to 75 months). Twenty five percent (25\%) of patients in CR before the transplant relapsed or progresses as did $41.6 \%$ of those in PR. Rescue therapy consisted of: chemotherapy in $6(16.6 \%)$, chemotherapy followed by alloHSCT in $2(5.5 \%)$ and $2(5.5 \%)$ only received palliative care.

After a median follow-up of 59 month, 24 patients are alive and disease-free, and 7 are alive with disease. The estimated 5 -year survival is $65 \%$ (56\% in $\mathrm{HL}$ and $69 \%$ in $\mathrm{NHL}$ ) and disease-free survival is $51 \%$ (53\% in HL and 54\% in NHL) (Figures 1 and 2). T-cell lymphomas were analyzed separately, yielding DFS and OS of $74 \%$ and $83 \%$, respectively (Figure 2 ).

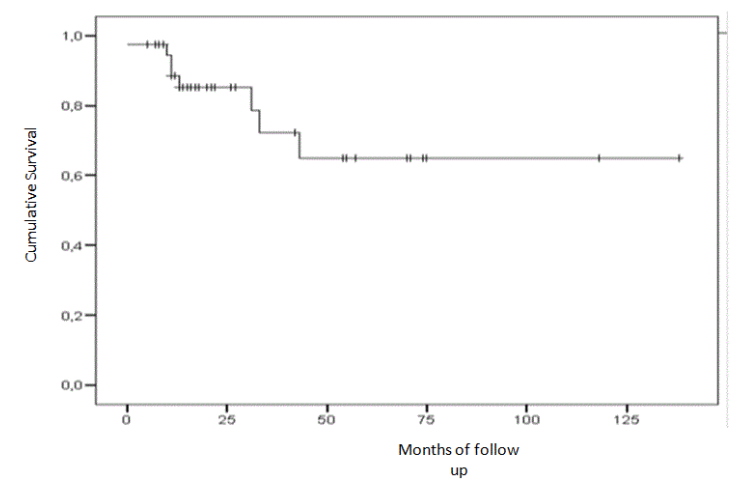

Figure 1: Overall Survival curves of adult with Lymphoma treated with transplantation. 


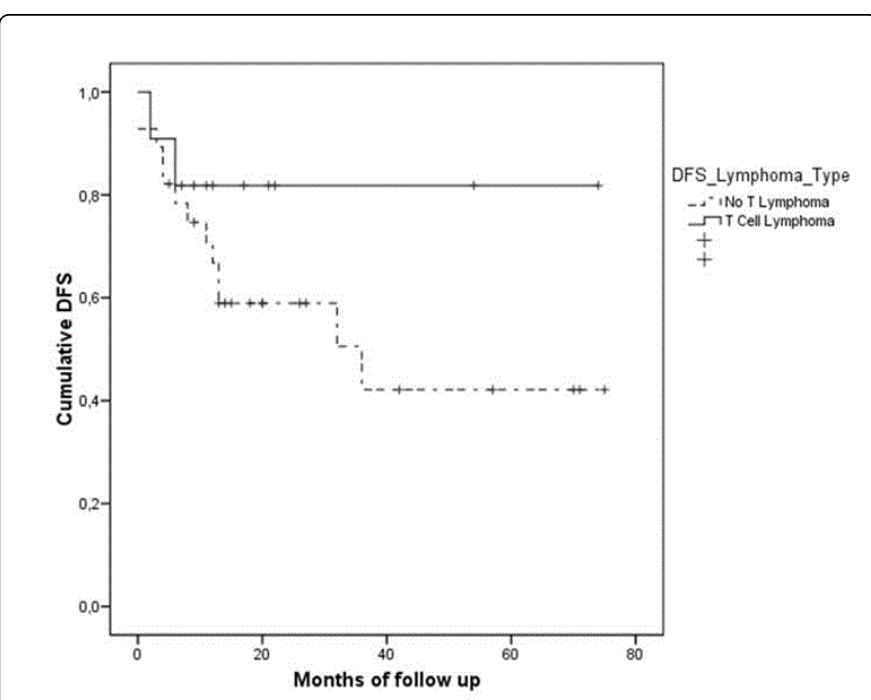

Figure 2: Disease free survival curves of adult with Lymphoma treated with transplantation.

\section{Prognostic factors}

Patients with a negative PET scan after transplant had a greater OS than those with a positive scan $(74 \%$ vs. $35 \%$, respectively); this difference was statistically significant (log rank=0.0001) (Figure 3). Moreover, patients in CR before the transplant had a greater OS than those transplanted while in PR or relapse ( $78 \%$ vs. $26 \%$ ), this was not statistically significant.

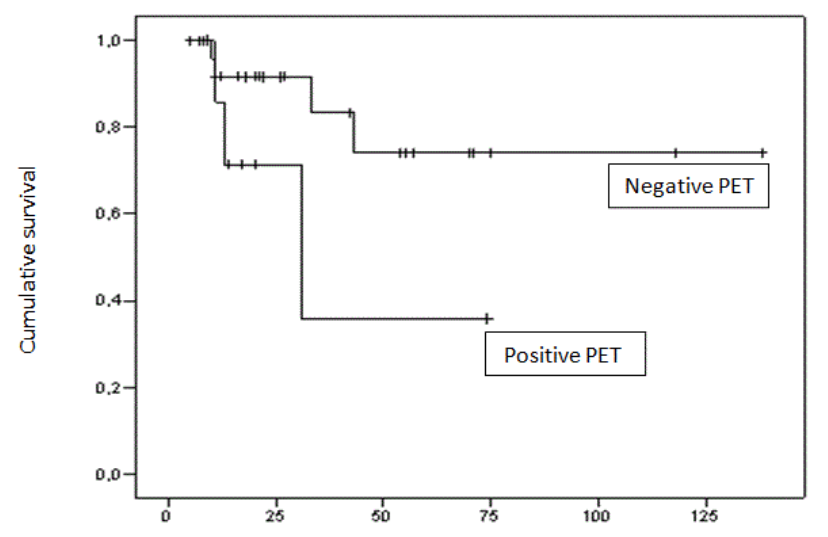

Figure 3: Overall survival curves of patients with negative PET after transplantation.

\section{Discussion}

In 2008, the incidence of lymphoma in Mexico was 5333 cases (4276 NHL and $1057 \mathrm{HL}$ ), representing $4.2 \%$ of all cancers during that period, and its five year prevalence was 10,945 cases [11]. NHL was the eighth cancer-related mortality cause in men in our country (3.5\%). The European Bone Marrow Transplant registry reported 7712 autologous transplants in the treatment of NHL and HL throughout
2011 [12]. There are no precise records in our country on the number of transplants performed per year due to these disease entities [13-16] because only recently has a transplant registry been established. However, the few published reports [12-15] reveal that the number of bone marrow transplants in our country is substantially inferior to the calculated number of autologous and allogeneic transplants required in Mexico, 1-49 per 10 million individuals [17].

The efficacy of HDC-AHSCT was demonstrated in the PARMA study, reporting a DFS of $46 \%$ and an OS of $53 \%$ in refractory or relapsing DLBC NHL in the era prior to the use of Rituximab [16] when compared with patients treated with conventional chemotherapy. Recently, the SWOG S9704 study [18] compared management with CT (CHOP/R-CHOP) vs. HDC-AHSCT in patients with intermediate-high and high IPI DLBC NHL, and reported benefits in transplanted patients in terms of DFS (56\% vs. 69\%, HR 1.7 (95\% CI 1.18-2.51) $\mathrm{p}=0.005)$. Also, the European Mantle Cell Lymphoma Network compared treatment with autologous transplant versus standard chemotherapy and maintenance with Interferon alpha; they found a greater progression-free survival in the transplanted group versus the maintenance group (39 versus 17 months, $\mathrm{p}=0.0108,95 \%$ CI 39-69) [19,20]. Tam et al. [21] reported an OS of 93 months and PFS of 42 months in patients with mantle lymphoma in first complete remission treated with high-dose chemotherapy and autologous transplant. The poor response of T-cell lymphomas to conventional chemotherapy has led to the study of autologous transplant as first-line consolidation treatment. Some retrospective studies have reported positive results with transplant in patients with peripheral T-cell NHL [22-25], with reported 3-year OS of $53 \%$ versus $58 \%$ and DFS of $53 \%$ versus $44 \%$ with HDC-AHSCT compared with CT. In the case of HL, Moskowitz [26] reported an OS of $66 \%$ in patients with chemosensitive disease prior to transplant and Sirohi et al. [27] found a 5-year OS of 59\% in patients in PR and of $79 \%$ in those in CR.

To our knowledge, this is the Mexican study with the longest follow-up period reporting mortality, 5-year disease-free survival and 5 -year overall survival of 3\%,51\% and $65 \%$ respectively, values similar to those in the previously mentioned published series.

Our Institute uses a modified BEAM conditioning regimen allowing the infusion of apheresis within the first days after cell collection, thus avoiding product cryopreservation and decreasing laboratory costs and patient hospitalization. Transplants are performed in positive pressure rooms and no special isolation measures are necessary (except for hand-washing and the use of a facemask) in order to decrease treatment costs; in spite of this, our results are similar to those reported by other groups with a median cost of $14,750 \mathrm{dls}$ per patient.

We reported a low number of patients with DLCB NHL (7\%). This could be explained because we have economic limitations to give rescue chemotherapy other than $\mathrm{CHOP}$. Also, the median age of these patients is 70 years and at INNSZ, the age limit for autologous transplants is 65 years.

Ten percent (10\%) of all NHL are T-cell lymphomas. Their prognosis is worse than that of B cell lymphomas and in general, they are less responsive to anthracycline-based therapy (63\% vs. $54 \%$ $(\mathrm{p}=0.004), 45 \%$ vs. $37 \%(\mathrm{p}=0.0004), 52 \%$ vs. $41 \%(\mathrm{p}<0.0001)$ in terms of CR, DFS and OS, respectively).26 These low response rates have led several groups to study the role of autologous transplants when these patients are in their first complete remission. In our center, 17 of 39 
transplanted patients had T-cell lymphomas. All patients with this diagnosis (except for those ALK+) undergo autologous transplant during the first complete remission. The OS and DFS in our patients is higher to that reported by other groups ( $73 \%$ and $73 \%$ respectively). Tandem autologous transplants in high-risk HL patients (refractory or at risk of relapse and two adverse risk factors) were studied by the French group "GELA/Société Française de Greffe de Moelle (SFGM) Working Group" who reported responses (CRu/CR/PR) of $63 \%$ in 55 patients with chemoresistant disease [28]. CR/CRu was achieved in $53 \%$. After a median follow-up of 51 months, freedom from second failure (FF2F) at 5 years was $46 \%$ and OS, $57 \%$. No differences were observed between patients with primary refractory disease or in relapse in terms of OS or FF2F. FF2F in patients with chemosensitive disease was $61 \%$ vs. $21 \%$ in those with chemoresistant disease $(\mathrm{p}<0.0001)$ and OS was 72 vs. 31 months $(\mathrm{p}<0.0001)$. At our Institute tandem autologous transplant program has been implemented for patients with HL and high relapse-associated risk factors. Our results are still premature but the three patients so treated are alive and in complete remission.

In our analysis, the PET-scan after transplantation was the only survival prognostic factor on multivariate analysis. This has been previously reported by other groups [17,29]. There is no information in Mexico to determine whether to perform PET is cost-effective. No statistical significance was found with other variables as reported by other groups but this may result from the small number of included patients.

In spite of the small number of patients included in our study and its retrospective design, and although our resources are limited, our results are similar to those in series analyzed in developed countries. Finally, our findings underscore the need to implement public policies in Mexico that will increase the number of patients benefitting from this therapeutic modality.

\section{References}

1. Siegel R, Naishadham D, Jemal A (2013) Cancer statistics, 2013. CA Cancer J Clin 63: 11-30.

2. http://www.epidemiologia.salud.gob.mx/doctos/infoepid/publicaciones/ 2011/monografias/P_EPI_DE_LOS_TUMORES_MALIGNOS_M \%C3\%A9xico.pdf .

3. Shankland KR, Armitage JO, Hancock BW (2012) Non-Hodgkin lymphoma. Lancet 380: 848-857.

4. Townsend W, Linch D (2012) Hodgkin's lymphoma in adults. Lancet 380: 836-847.

5. Punnett A, Tsang RW, Hodgson DC (2010) Hodgkin lymphoma across the age spectrum: epidemiology, therapy, and late effects. Semin Radiat Oncol 20: 30-44.

6. Schmitz N, Pfistner B, Sextro M, Sieber M, Diehl V, et al. (2002) Aggressive conventional chemotherapy compared with high-dose chemotherapy with autologous haemopoietic stem cell transplantation for relapsed chemosensitive Hodgkin disease: a randomized trial. The Lancet 359: 2065-2071.

7. Linch DC, Winfield D, Goldstone AH, Moir D, Hancock B, et al. (1993) Dose intensification with autologous bone-marrow transplantation in relapsed and resistant Hodgkin's disease: results of a BNLI randomised trial. Lancet 341: 1051-1054.

8. Cheson BD, Pfistner B, Juweid ME, Gascoyne RD, Specht L, et al. (2007) Revised response criteria for malignant lymphoma. J Clin Oncol 25: 579-586.

9. Meignan M, Gallamini A, Haioun C, Polliack A (2010) Report on the Second International Workshop on interim positron emission tomography in lymphoma held in Menton, France, 8-9 April 2010. Leuk Lymphoma 51: 2171-2180.

10. Sorror ML, Maris MB, Storb R, Baron F, Sandmaier BM, et al. (2005) Hematopoietic cell transplantation (HCT)-specific comorbidity index: a new tool for risk assessment before allogeneic HCT. Blood 106: 2912-2919.

11. Horwitz SM (2007) Management of peripheral T-cell non-Hodgkin's lymphoma. Curr Opin Oncol 19: 438-443.

12. Passweg JR, Baldomero H, Bregni M, Cesaro S, Madrigal A, et al. (2013) Hematopoietic SCT in Europe: data and trends in 2011. Bone Marrow Transplantation 48: 1-7.

13. Gutiérrez-Aguirre $\mathrm{CH}$, Ruiz-Argüelles $\mathrm{G}$, Cantú-Rodríguez $\mathrm{OG}$, González-Llano O, Gómez-Almaguer D, et al. (2010) Outpatient reduced- intensity allogeneic stem cell transplantation for patients with refractory or relapsed lymphomas compared with autologous stem cell transplantation using a simplified method. Annals of Hematology 89: 1045-1052.

14. Ruiz-Argüelles GJ, Gómez-Rangel D, Ruiz-Delgado GJ, Ruiz-Argüelles A, Pérez- Romano B, et al. (2003) Results of an autologous noncryopreserved, unmanipulated peripheral blood hematopoietic stem cell transplant program: a single-institution, 10 year experience. Acta Haematologica 110: 179-183.

15. Delgado-Lamas JL, Garcés-Ruiz OM, Rubio-Jurado B (2000) [Hematopoietic cell transplantation. Experience at the Western National Medical Center]. Rev Invest Clin 52: 234-240.

16. Ruiz-Argüelles GJ, Ruiz-Argüelles A, Pérez-Romano B, Marín-López A, Larregina-Díez A, et al. (1995) Filgrastim-mobilized peripheral-blood stem cells can be stored at 4 degrees and used in autografts to rescue high-dose chemotherapy. Am J Hematol 48: 100-103.

17. Zijlstra JM, Lindauer-van der Werf G, Hoekstra OS, Hooft L, Riphagen II, et al. (2006) 18F-fluoro-deoxyglucose positron emission tomography for post-treatment evaluation of malignant lymphoma: a systematic review. Haematologica 91: 522-529.

18. Philip T, Chauvin F, Fernandez-Ranada J, Armitage J, Bron D, et al. (1991) Parma international protocol: pilot study of DHAP followed by involved-field radiotherapy and BEAC with autologous bone marrow transplantation. Blood 77: 1587-1592.

19. Stiff PJ, Unger JM, Cook J, Constine LS, Couban S, et al. (2011) Fisher Randomized phase III U.S./Canadian intergroup trial (SWOG S9704) comparing $\mathrm{CHOP} \pm \mathrm{R}$ for eight cycles to $\mathrm{CHOP} \pm \mathrm{R}$ for six cycles followed by autotransplant for patients with high-intermediate (H-Int) or high IPI grade diffuse aggressive non-Hodgkin lymphoma (NHL). Journal of Clinical Oncology, 2011 ASCO Annual MeetingAbstracts 29: 15.

20. Dreyling M, Lenz G, Hoster E, Van Hoof A, Gisselebrecht C, et al. (2005) Early consolidation by myeloablative radiochemotherapy followed by autologous stem cell transplantation in first remission significantly prolongs progression free survival in mantle cell lymphoma: results of a prospective randomized trial of the European MCL Network. Blood 105: 2677-2684.

21. Tam CS, Bassett R, Ledesma C, Korbling M, Alousi A, et al. (2009) Mature results of the M. D. Anderson Cancer Center risk-adapted transplantation strategy in mantle cell lymphoma. Blood 113: 4144-4152.

22. Feyler S, Prince HM, Pearce R, Towlson K, Nivison-Smith I, et al. (2007) The role of high-dose therapy and stem cell rescue in the management of T-cell malignant lymphomas: a BSBMT and ABMTRR study. Bone Marrow Transplant 40: 443-450.

23. Jantunen E, Wiklund T, Juvonen E, Putkonen M, Lehtinen $\mathrm{T}$, et al. (2004) Autologous stem cell transplantation in adult patients with peripheral T-cell lymphoma: a nation-wide survey. Bone Marrow Transplant 33: 405-410.

24. Yang DH, Kim WS, Kim SJ, Bae SH, Kim SH, et al. (2009) Prognostic factors and clinical outcomes of high-dose chemotherapy followed by autologous stem cell transplantation in patients with peripheral $\mathrm{T}$ cell lymphoma, unspecified: complete remission at transplantation and the 
Citation: Karla AEB, Alejandra AA, Andrea CS, Sandra IPA, Eucario L (2015) Autologous Transplant in Lymphoma: Experience in a Limited Resource Mexican Reference Center . J Blood Disorders Transf 6: 266. doi:10.4172/2155-9864.1000266

Page 6 of 6

prognostic index of peripheral $\mathrm{T}$ cell lymphoma are the major factors predictive of outcome. Biol Blood Marrow Transplant 15: 118-125.

25. Rodríguez J, Conde E, Gutiérrez A, Arranz R, León A, et al. (2007) Frontline autologous stem cell transplantation in high-risk peripheral Tcell lymphoma: a prospective study from The Gel-Tamo Study Group. Eur J Haematol 79: 32-38.

26. Moskowitz CH, Kewalramani T, Nimer SD, Gonzalez M, Zelenetz AD, et al. (2004) Effectiveness of high dose chemoradiotherapy and autologous stem cell transplantation for patients with biopsy-proven primary refractory Hodgkin's disease. Br J Haematol 124: 645-652.

27. Sirohi B, Cunningham D, Powles R, Murphy F, Arkenau T, et al. (2008) Long-term outcome of autologous stem-cell transplantation in relapsed or refractory Hodgkin's lymphoma. Ann Oncol 19: 1312-1319.
28. Morschhauser F, Brice P, Gisselebrecht C, Fermé C, Diviné M, et al. (2008) Risk-adapted Salvage Treatment with Single or Tandem Autologous Stem-Cell Transplantation for First Relapse/Refractory Hodgkin Lymphoma: Results for the Prospective Multicenter H96 Trial by The GELA/SFGM Study Group. Journal of Clinical Oncology 26: 5980-5987.

29. Terasawa T, Nihashi T, Hotta T, Nagai H (2008) 18F-FDG PET for posttherapy assessment of Hodgkin's disease and aggressive NonHodgkin's lymphoma: a systematic review. J Nucl Med 49: 13-21. 